\title{
Photoswitchable dye-nanoparticle probes with photothermal switching of light-dark states and colors (Withdrawal Notice)
}

Walter Harrington, Mwafaq Haji, Ekaterina Galanzha, Dmitry Nedosekin, Zeid Nima, et al.

Walter Harrington, Mwafaq R. Haji, Ekaterina I. Galanzha, Dmitry A. Nedosekin, Zeid A. Nima, Fumiya Watanabe, Anindya Ghosh, Alexandru S. Biris, Vladimir P. Zharov, "Photoswitchable dye-nanoparticle probes with photothermal switching of light-dark states and colors (Withdrawal Notice)," Proc. SPIE 10079, Reporters, Markers, Dyes, Nanoparticles, and Molecular Probes for Biomedical Applications IX, 100790D (21 February 2017); doi: $10.1117 / 12.2254991$ 


\title{
Photoswitchable dye-nanoparticle probes with photothermal switching of light-dark states and colors (withdrawal notice)
}

\author{
Proc. SPIE 10079, 100790D (2017) \\ Online Publication Date: 21 February 2017 \\ Withdrawn from Publication: 12 April 2017 \\ Conference Date: 30 January -2 February March 2017 \\ Conference Location: San Francisco, California, United States \\ Conference Title: Reporters, Markers, Dyes, Nanoparticles, and Molecular Probes for Biomedical \\ Applications IX \\ Conference Chairs: Samuel Achilefu, Ramesh Raghavachari \\ Walter Harrington \\ Univ. of Arkansas for Medical Sciences, United States
}

This paper was withdrawn at the author's request due to errors.

Reporters, Markers, Dyes, Nanoparticles, and Molecular Probes for Biomedical Applications IX edited by Samuel Achilefu, Ramesh Raghavachari, Proc. of SPIE Vol. 10079, 100790D

(C) 2017 SPIE · CCC code: 1605-7422/17/\$18 · doi: 10.1117/12.2254991 